\title{
THE USE OF I.P.P.V. IN TWO CASES OF PULMONARY OEDEMA
}

\author{
Major R. O. WALTERS, M.B., B.S., D.C.H., D.T.M.\&H., R.A.M.C. \\ Major J. ANDERSON, M.B., Ch.B., R.A.M.C. \\ Military Hospital, Colchester
}

\begin{abstract}
SUMMARY: Two cases of pulmonary oedema managed with Intermittent positive-pressure ventilation (I.P.P.V.), using an East Radcliffe Ventilator, are presented. One of the cases illustrates the use of the Royal Air Force Type 1 d.c. defibrillator for cardioversion in an emergency situation.
\end{abstract}

Case 1

\section{Case histories}

A fifty year old male serving officer was admitted for a left inguinal herniorraphy. He gave a history of recent chest trauma and admitted to heavy smoking; on examination, he was moderately overweight but had no abnormal physical signs; B.P. 150/80; chest $\mathrm{X}$-ray was normal; he was considered fit for general anaesthesia.

Anaesthetic history. Premedication; Omnopon $20 \mathrm{mg}$, scopolamine $0.4 \mathrm{mg}$, given intramuscularly, one hour prior to operation with effect. Induction; thiopentone $500 \mathrm{mg}$ of a 2.5 per cent solution and pancuronium $6 \mathrm{mg}$. He was intubated, maintained with oxygen 3 litre/min, nitrous oxide 6 litre $/ \mathrm{min}$, using a Manley ventilator with a tidal volume of $600 \mathrm{ml}$ at an inflation pressure of $15 \mathrm{~cm} \mathrm{H}_{2} \mathrm{O}$, analgesic supplement, Fortral $60 \mathrm{mg}$.

The operation proceeded uneventfully and after 45 minutes, the paralysis was reversed using atropine $0.6 \mathrm{mg}$ and neostigmine $2.5 \mathrm{mg}$. A surgical delay necessitated the administration of halothane for a brief period, before the patient was removed to the adjacent recovery ward, where, one to two minutes later he collapsed, became cyanosed and convulsed. On examination, pulse 100/min, regular, B.P. 100/40; marked bronchospasm with peripheral cyanosis; Electrocardiogram (e.c.g.) showed sinus rhythm with repolarisation changes suggestive of anterior ischaemia; blood gas estimation at this time showed $\mathrm{pH} 7.11: \mathrm{pCO}_{2} 70 \mathrm{~mm} / \mathrm{Hg}$; standard bicarbonate $18 \mathrm{mEq} / \mathrm{litre}$.

Resuscitátion commenced immediately, difficulty was experienced in obtaining adequate ventilation, and the patient was intubated and ventilated with 100 per cent oxygen. Other measures included the intravenous administration of hydrocortisone $200 \mathrm{mg}$; sodium bicarbonate $(8.4$ per cent) $100 \mathrm{ml}$, and mannitol (20 per cent) $200 \mathrm{ml}$; the intravenous infusion was maintained with Hartmann's solution. The patient was catheterised and then transferred to the Intensive Care Unit where a chest X-ray showed gross pulmonary oedema. This was treated by ventilation using an East Radcliffe Ventilator with entrained oxygen at 8 litre/min; tidal volume $750 \mathrm{ml}$; rate $20 / \mathrm{min}$ and inflation pressure $30 \mathrm{~cm} \mathrm{H}_{2} \mathrm{O}$; paralysis being maintained with intravenous pancuronium $2 \mathrm{mg}$ hourly and sedation with intravenous phenoperidine $1 \mathrm{mg}$ hourly. Frusemide was also administered intravenously to promote diuresis. The patient had a good diuresis and was successfully extubated after 24 hours of I.P.P.V. and subsequently made an uneventful recovery. Serial e.c.g's have continued to show the polarisation changes of anterolateral ischaemia, without evidence of infarction. 


\section{Case 2}

A fifty-nine year old man was admitted, having collapsed at work. He had been known to have had atrial fibrillation and hypertension for four years; he had been on Digoxin during this period and the dosage at the time of admission was $0.25 \mathrm{mg}$ b.d.

On admission he was not shocked, and was not in pain; pulse $120 / \mathrm{min}$; atrial fibrillation, B.P. 140/90, the heart sounds were normal with no murmurs, the lung fields were clear, and there was no evidence of heart failure. Serum potassium was 3.8 $\mathrm{mEq} /$ litre. Plasma Digoxin $3.0 \mathrm{ng} / \mathrm{ml}$. Twenty minutes after admission the patient collapsed and became deeply cyanosed with no discernible pulse whilst being prepared for monitoring. External cardiac massage and exhaled ventilation was carried out by the nursing staff with the restoration of a heart beat and gasping respiration.

It proved impossible to achieve adequate ventilation, blood gas estimation showed

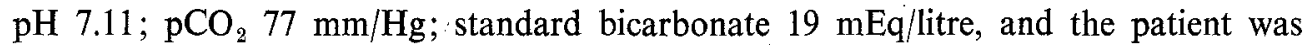
paralysed, intubated and ventilated with 100 per cent oxygen. Following intubation, the characteristic blood stained froth of severe pulmonary oedema poured from the tube. In view of this he was ventilated using an East Radcliffe Ventilator with entrained oxygen at 8 litre $/ \mathrm{min}$; tidal volume of $750 \mathrm{ml}$; rate $20 / \mathrm{min}$ and inflation pressure $30 \mathrm{~cm}$ $\mathrm{H}_{2} \mathrm{O}$, paralysis being maintained with intravenous pancuronium $2 \mathrm{mg}$ hourly and sedation with intravenous phenoperidine $1 \mathrm{mg}$ hourly.

An intravenous infusion was established, and the patient was catheterised. The metabolic acidosis was corrected using intravenous sodium bicarbonate 8.4 per cent, diuresis was obtained with intravenous frusemide and additional potassium was given by intravenous infusion. Ventilation improved steadily and no further problems were encountered with this aspect of management. Various supra ventricular cardiac arrythmias were observed over the course of the next 45 minutes; these were controlled with intravenous practolol $20 \mathrm{mg}$, and intravenous phenytoin sodium $250 \mathrm{mg}$, with improvement of cardiac output. Subsequent ventricular ectopics were controlled with an intravenous infusion of lignocaine. Cardiac irregularity continued to be observed but presented no problems until the following day, when the patient had a further circulatory collapse, with a heart rate of $160 / \mathrm{min}$, B.P. $80 / 40$. Runs of ventricular tachycardia were controlled with an intravenous infusion of lignocaine $2.5 \mathrm{mg} / \mathrm{min}$, but intravenous practolol $10 \mathrm{mg}$ failed to influence the persistent junctional rhythm which had supervened on atrial fibrillation (Fig. 1). Isoprenaline was infused intravenously at a rate of $4 \mu \mathrm{g} / \mathrm{min}$

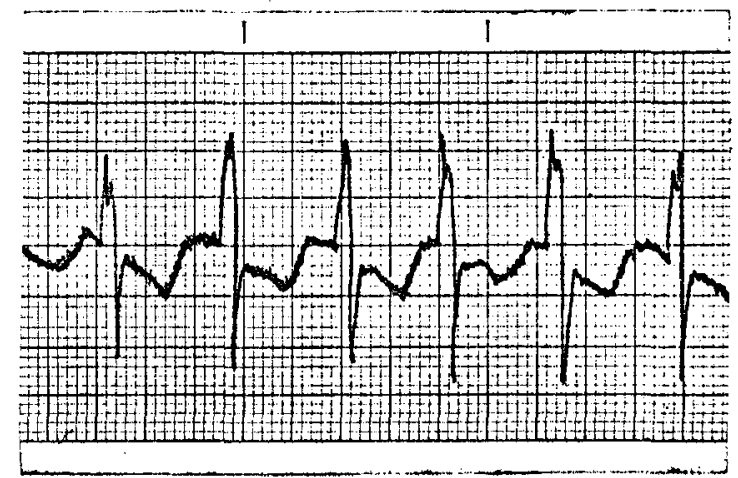

Fig. 1. Electrocardiogram of Case 2 showing the persistent junctional rhythm which had supervened on atrial fibrillation. 
and in the absence of a facility for performing cardioversion with synchronised d.c. shock, unsynchronised d.c. shock was applied with a setting of 60 joules, without effect. It was reapplied with a setting of 80 joules with restoration of sinus rhythm. Isoprenaline was discontinued immediately and the intravenous infusion of lignocaine was restarted to prevent ventricular ectopic beats; the patient was anticoagulated with intravenous heparin. Sinus rhythm was maintained (Fig. 2), and three hours later I.P.P.V. was

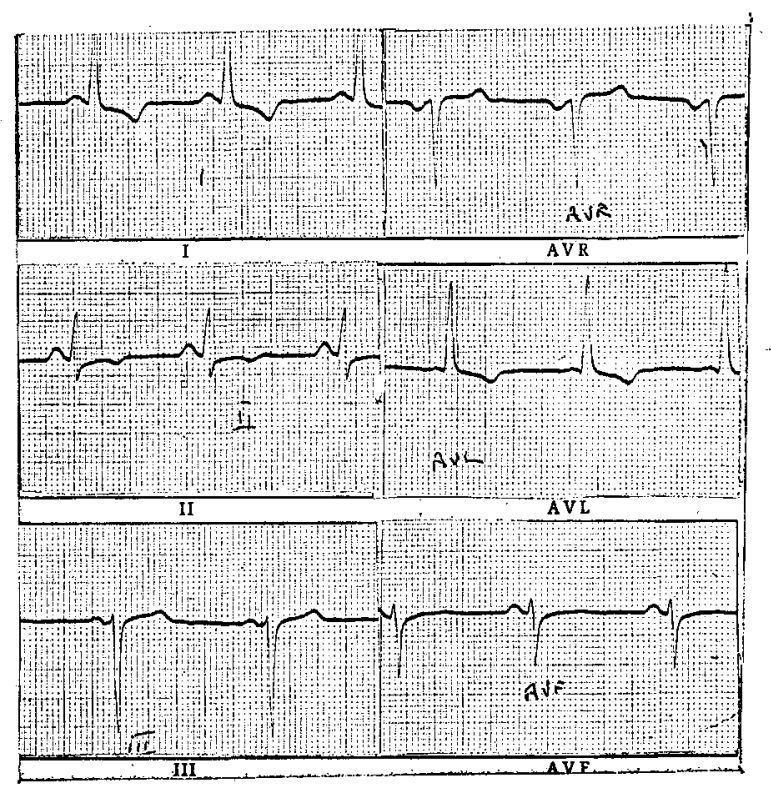

Fig. 2. Electrocardiogram of Case 2 showing restoration of sinus rhythm after shock treatment.

discontinued and the patient extubated without disturbance to the cardiac rythhm. Subsequently the patient made a good recovery, remaining in sinus rhythm with a good cardiac output and no evidence of heart failure.

\section{Discussion}

In both cases, we believe that the sudden left ventricular failure causing acute pulmonary oedema resulted from drug induced cardiac arrhythmias in patients who have evidence of underlying myocardial ischaemia. Early I.P.P.V. with the East Radcliffe Ventilator in the presence of cardiac decompensation ensures:-

a. A safe airway. b. Improved and more uniform pulmonary ventilation. c. An increase in alveolar pressure which reduces the transudation of fluid into the alveoli, and reduces the venous return leading to a fall in the pulmonary arterial pressure. Consequently the left ventricular end diastolic pressure falls with a reduction of the work load on the myocardium. $d$. The lungs become less stiff and the work of breathing is reduced, when unassisted ventilation is restored. e. On balance oxygenation is improved although the fall in cardiac output does lead to a fall in the delivery of oxygen to the tissues.

In both cases described I.P.P.V. together with frusemide intravenously dramatically reduced the effects of acute left ventricular failure and allowed for correction of the acid-base imbalance. In addition the early use of I.P.P.V. allowed the heart to be 
isolated from the strain of coping with the disordered respiration and enabled the treatment of the underlying cardiac condition to be carefully considered. In neither case was a positive end expiratory pressure needed. The incidence of ventricular arrhythmias as a result of exposure to halothane especially in the presence of hypercapnia has been well documented. Case 1 is another good example of this and illustrates the necessity of maintaining good ventilation to prevent hypercapnia during halothane anaesthesia and the subsequent recovery period.

Many disturbances of heart rhythm mày occur as a result of digitalis toxicity. In Case 2, a variety of arrhythmias characteristic of digitalis toxicity in the presence of myocardial disease were obseerved; of these a junctional rhythm supervening on atrial fibrillation and ventricular tachycardia are the most characteristic. The plasma digoxin level on admission of $3.0 \mathrm{ng} / \mathrm{ml}$ is strong confirmatory evidence of digitalis toxicity although because of multifactorial determinants of digoxin toxicity there is no clearly defined toxic level. In this case the occurrence of a life threatening arrhythmia which could not be controlled by drugs led us to attempt cardioversion, in the absence of a facility for synchronised d.c. shock, with the Royal Air Force Type 1 d.c. defibrillator.

Isoprenaline was infused prior to the attempt firstly with the idea of increasing the ventricular rate thereby increasing the chance of delivering the d.c. impulse on the downstroke of an $\mathbf{R}$ wave when supraventricular arrhythmias are most responsive, and secondly in the hope that if the d.c. impulse led to ventricular fibrillation this might be more responsive to a further unsynchronised d.c. shock. Our experience leads us to suggest that unsynchronised d.c. shock may be better than no shock at all in the termination of a life threatening supraventricular arrhythmia.

\section{ACADEMIC ACHIEVEMENTS}

M.Sc. (Periodontology)

F.F.R.

D.Obst.R.C.O.G.

Dip. Derm.
MAJOR T. F. WALSH, B.D.S., R.A.D.C.

MAJOR M. F. HURLeY, M.B., B.Ch., D.M.R.D., R.A.M.C.

Lieutenant-Colonel. T. D. Jones, M.B., B.ch., R.A.M.C.

MAJOR E. MIrSUD, M.D., R.A.M.C. 